\title{
Work Integrated Learning (WIL): A Phenomenographic Study Of Student-Teachers' Experiences
}

\author{
Thomas Edwin Buabeng Assan \\ North-West University, Mafikeng Campus, South Africa \\ thomas.assan@nwu.ac.za
}

\section{Doi:10.5901/mjss.2014.v5n7p300}

\section{Abstract}

The study investigated the work integrated learning (WIL) experiences of final year PGCE and BEd student teachers. The study sample consisted of 50 student-teachers selected randomly from 165 final year BEd and PGCE students. Each student was requested to complete an open-ended questionnaire based among other things on the issues which formed the object of the study. In-depth interviews were also held with 10 of the respondents selected randomly. Inputs from 10 purposively randomly selected schools were also considered. A phenomenographic method of data collection and analysis was employed. The results showed that around $50 \%$ of the students-teachers were not ready and not motivated to become teachers due to the following: learner indiscipline; lack of confidence due to subject content inadequacy; resources and facilities in schools not conducive to effective teaching; lack of support from some mentors; lack of adequate preparation before being sent to schools, for example on the use of LTSM (Learning-Teaching Support Material), chalkboard practice, lesson planning, development and presentation; lecturers who do not visit regularly, and in some cases students felt alienated when on practice. The study however highlighted the following for improvement in the WIL to stimulate student-teacher interest and effectiveness: strengthen the content delivery to build more confidence among learners, strengthen the pedagogical approaches to improve student-teacher knowledge and skills in inclusive teaching, human development and learning, curriculum management, etc. and improving the work experience practices to enhance students skills in the use of chalkboard, LTSM, lesson planning, development and implementation.

Keywords: Work Integrated Learning (WIL); Bachelor of Education (BEd); Post Graduate Certificate in Education (PGCE); Studentteachers, Department of Education; Higher Education Qualification Sub-framework (HEQSF); Learning and Teaching Support Material (LTSM).

\section{Introduction}

The current generation of South African teachers is the first to experience the new non-racial, democratic transformation of the education system. The schooling system needs both more teachers and better teachers: more teachers, qualified and competent enough to teach specific subjects or learning areas, in specific phases, in specific languages, in all schools, including special schools (The Departments of Basic Education \& Higher Education and Training, 2011). According to Department of Education, (2006) this policy is underpinned by the belief that teachers are the essential drivers of a good quality education system. International evidence shows that the professional education and development of teachers' works best when teachers themselves are integrally involved in it, reflecting on their own practice; when there is a strong school-based component; and when activities are well co-ordinated. The aim of teacher education in South Africa is to properly equip teachers to undertake their essential and demanding tasks, to enable them to continually enhance their professional competence and performance, and to raise the esteem in which they are held by the people of South Africa The teacher has strategic importance for the intellectual, moral, and cultural preparation of our young people. Teachers are the largest single occupational group and profession in the country, numbering over 390000 in public and private schools (Department of Education, 2006).

\section{Significance of the Study}

Since 1994 the South African democratic government's investment in education has reached nearly 8\% of the Gross Domestic Product (GDP) by 2013. Compared to the rest of the continent, South Africa comes first in terms of the proportion of the GPD spent on all levels of education. In 2013 for example, the South African government spent 21\% of the National Budget on education alone. However this massive resource allocation to education has not seen any 
proportionate increase in learner performance. In the current South African context, learner performance is a critical output indicator of the education system that is related to the curriculum. The low throughput at universities further gives an indication that schooling does not meet the requirement of economy. For example, the national assessments for grades 3 and 6 pupils over the past five years in Mathematics and Literacy have yielded a national average score of below 50\% in these subjects. In 2012 only 13.7\% passed Mathematics with 40\% and above in the National Senior Certificate Examinations. This research study and various others have shown that, South African education system is still bestowed with lots of challenges such that more effort is required to raise the standard of learning and teaching. The significance of the study is based on the fact that the Department of Higher Education has upgraded the teacher education qualification on the HEQSF (Higher Education Qualification Sub-framework) to level 7/8 and universities are expected to register new B.Ed. and ADT (Advanced Diploma in Teaching, which replaces the current PGCE) qualifications based on the new qualification framework. This study focused on the experiences of student-teacher during their WIL. These findings should assist efforts to improve education standards with respect to teacher training.

\section{Literature Review}

\subsection{The conceptual framework}

The principle underlining teacher education policy in South Africa is based on Integrated and applied knowledge. This principle is explained as the condition for, and the effect of scrutinising, fusing together and expressing different types of knowing in the moment of practice. The principle of applied and integrated knowledge implies that these different kinds of learning should be integrated across courses and modules, so as to ensure that they serve the purpose of the teacher education programme. The following explanations are summaries describing these concepts according to the policy on minimum requirements on Teacher Education Qualification (Department of Higher Education and Training, 2011):

Work integrated learning refers to the variety of classroom and school experiences to which student-teachers are exposed. These experiences are the combinations of different conceptual learning practices as explained below. The overall purpose of WLL at the institution of the research study is to expose student-teachers to the actual teaching and learning environment (Marais \& Meier, 2004).

Disciplinary Learning, refers to disciplinary or subject matter knowledge, and can be presented in two components within a teaching curriculum, namely the study of education and its foundations, including but not limited to the philosophy, psychology, politics, economics, sociology and history of education; and the study of specific specialised subject matter that is relevant to the academic disciplines underpinning teaching subjects or specialisations (Capel, Leask \& Turner, 2013). Pedagogic Learning includes 'knowledge of learners, learning, curriculum and general instructional and assessment strategies; and specialised pedagogical content knowledge, which includes knowing how to represent the concepts, methods and rules of a discipline in order to create appropriate learning opportunities for diverse learners, as well as how to evaluate their progress. Inclusive education forms an important aspect of both general pedagogical knowledge and specialised pedagogical content knowledge' (Jephcote \& Abbott (2005).

Practical Learning involves learning in and from practice. 'Learning from practice includes the study of practice, using discursive resources to analyse different practices across a variety of contexts, drawing from case studies, video records, lesson observations, etc., in order to theorise practice and form a basis for learning in practice. Learning in practice involves teaching in authentic and simulated classroom environments. Work-integrated learning (WIL) takes place in the workplace and can include aspects of learning from practice (e.g. observing and reflecting on lessons taught by others), as well as learning in practice (e.g. preparing, teaching and reflecting on lessons presented by oneself). Practical learning is an important condition for the development of tacit knowledge, which is an essential component of learning to teach'. In this instance work integrated learning becomes part of practical learning (Cohen, Manion, Morrison, \& Wyse, 2010).

Fundamental Learning. According to the Department of Higher Education and Training (2011) Fundamental Learning in the South African context refers "to learning to converse competently in a second official language, the ability to use Information and Communication Technologies (ICTs) competently, and the acquisition of academic literacies, which lay the foundation for effective learning in higher education contexts." Fundamental learning provides the point of departure for effective work integrated learning.

Situational Learning, refers to 'knowledge of the varied learning situations, contexts and environments of education (classrooms, schools, communities, districts, regions, countries and globally), as well as to prevailing policy, political and organisational contexts. Naturally, all learning - including Disciplinary Learning, Pedagogical Learning, Practical Learning and Fundamental Learning - should involve learning in context, but situational learning refers specifically to learning 
about context (Cohen, Manion, Morrison, and Wyse, 2010). This includes an understanding of the complex and differentiated nature of South African society; learning to work in nuanced ways with the diverse challenges faced by children in schools and the communities that they serve, for example HIV and AIDS, poverty and the lingering effects of apartheid; dealing with diversity; promoting inclusivity; and environmental sustainability'. The influence of situational learning on the work integrated learning experience was huge in this study, because to a large extent it impacted on a student-teacher's decision to consider teaching as a profession.

Phenomenographic study examines how people experience, understand and ascribe meaning to a specific situation or phenomenon (Marton \& Booth, 1997). The experience as such contains both a "what" (object) aspect and a "how" (act) aspect related to the work integrated learning phenomenon. Phenomenographic research has moved on to attempt to address questions such as 'what is "a way of experiencing something"?' or 'what is the actual difference between two "ways of experiencing the same thing"?' (Marton \& Pang, 1999). In this study the respondent studentteachers had the opportunity to describe their experiences as they attempt to apply their disciplinary, pedagogical learning within a situational context in order to acquire and improve upon experiential learning.

\subsection{Learning from Practice}

Flick \& Lederman (2001) make the point that the implications of the question "how do teachers learn from practice?" go to the heart of current efforts to implement acceptable academic standards in science and mathematics education. These standards, they contend, are not only concerned with what one teaches, but also with how one teaches. They continue that developing expertise in the form of complex instruction requires a view of work integrated learning as a discipline.

According to Papier (2008), Government lays down the structural and curriculum changes for universities, colleges, schools, public and private training providers. However, how the education academics take up the curriculum directives embedded in the new education policies into their programmes may depend upon a particular 'knowledge base' held by these academics. Papier (2008) is of the opinion that when the activity systems theory and the communities of practice merge, it is understood that whilst academic responses may be personal and individual, they take place within smaller activity systems such as Faculty work groups which begin to constitute communities of practice that shape them (and are shaped) through interaction, aspects of which may become the basis for understanding the origins of a particular practice. Academic responses to the curriculum frameworks are influenced by pedagogies, beliefs, characterised by strong academic identities, assumptions of common purpose (Papier, 2008). Curriculum content and pedagogical process were not prescribed under the Norms and Standards of education hence competencies were so extensive that it was unlikely that a beginning teacher would have acquired them all without effective training and development (Papier, 2008). However the main advantage of a non-prescriptive curriculum and pedagogical processes is that education in the South African context can be presented with a holistic view, considering the complexities of the teaching and learning process (Fraser, Killen \& Nieman, 2005).

\section{Problem Statement}

Work integrated learning (WIL) is a component of the Bachelor of Education (B.Ed.) as well as the Post Graduate Certificate in Education (PGCE) programmes for student-teachers. It is a requirement for these qualifications in the initial Teacher Education curriculum in South Africa. With their 4-year teacher education B.Ed. programme, student-teachers have to undergo at least 20 weeks of practical training to meet the qualification requirements at the University in which this study was conducted. The PGCE students on the other hand are enrolled for one-year full-time or two-year part-time contact classes and are currently required to undergo 12 weeks WIL (among other things) to qualify for the degree.

According to Kiggundu \& Nayimuli (2009) work integrated learning is a requirement to achieve the standards required for qualified teacher status, and a student-teacher is required to do work integrated learning in at least two school subjects. Work integrated learning according to Perry (2004) is aimed at inducting student-teachers more fully into the professional work of teachers. In their findings, Kiggundu \& Nayimuli (2009) established that theory acquired during university lectures provided student-teachers with enough information on how to teach; it was the work integrated learning that introduced them and gave them the exposure to the experiences of the real teaching world. In this study three main research questions were posed to the student teachers. The schools' representatives, normally the mentors and/or Departmental Heads were also requested to complete an open-ended form modified around the three research questions for the student-teachers sampled. The questions posed were as follows:

- What were the positive aspects of your work integrated learning experience?

- What were the constraints you experienced 
- What suggestions can you give to improve work integrated learning in general

\section{Research Methods}

\subsection{Participants}

This study was done to determine their experiences of WIL, and their impact on the student-teacher's continued desire to become a professional teacher. The study explored the issues raised in the research questions among a group of students who had completed their final work integrated learning: issues such as the positive aspects of WIL, the challenges experienced during their self-evaluation of WIL, and suggestions for improvements. The study sample consisted of 50 student-teachers selected randomly from 165 final year B.Ed. and PGCE students. Forty seven (47) students returned the completed open-ended questionnaire. Interviews were randomly conducted; selection was based on whether the responses given required further details and then the student was invited for interview. In total 10 students were interviewed. Each student was requested to complete an open-ended questionnaire based among other things on the issues which formed the object of the study.

\subsection{Instruments}

A phenomenographic method of data collection and analysis was employed, phenomenographic in the sense that respondents presented their statements in their own ways and the ways they had experienced the phenomenon. A sample of their assessment reports were also analysed to triangulate the responses. The focus of the study was on PGCE and final year BEd students. The data analysis process aimed at determining if the data from the questionnaires and interviews with the selected student-teachers provided insight into their experiences encountered in the classrooms and schools. The valuable, rich and authentic data from the student-teachers are provided below in the form of direct extracts. The summary or interpretation of the student teachers' accounts is presented under the different themes:

\section{Findings and Discussions}

The stories that the student-teachers tell relate to the experiences they encountered during the work integrated learning exercise and are made up of individual qualitative expressions of events that take place in their lives that are defined by their professional training and responsibilities. These stories reflect on their confusions, indecisions, insecurities, contradictions, fears, joys, successes, fateful moments, and most of all, their complex lives as student-teachers in the democratic dispensation (Mpungose, 2010). The findings are presented according to themes derived from the key research questions of the study as follows:

\subsection{What are the positive aspects of your work integrated learning?}

When the student-teachers were asked what aspects were considered to be beneficial and adequate for the acquisition of the teaching skills, out of the 47 respondents, 8 said they received respect_from learners. These were some of the respondents' comments: A student said: I had good relationship with the staff at the school and learners. I was respected by learners and staff. Another student stated: The environment is good/conducive for learners to learn. The teachers treat learners with love. I was treated well with respect by learners and also educators.

Twenty three (23) said the principals and staff of the schools where they were placed were supportive, helpful and co-operative and the schools provided all the necessary materials needed for their practice. This is what some of the respondents said. I had a supportive mentor and the ....staff welcomed me with warm hands and were helpful during my practicals. Another respondent commented: I was overwhelmed by the support I had from educators and they encouraged me a lot and asked me to come back to the school after completing.

Sixteen (16) student teachers expressed the fact that the work integrated learning gave them confidence_and this is what some of them said: student A: teachers were very helpful and they made me believe in myself by motivating me to believe myself and by motivating me to be confident enough to be in front of the learners. Student $\mathrm{F}$ said: I was overwhelmed by the support I had from educators and they encouraged me a lot asked me to come back to the school after my course. 


\subsection{What are the constraints experienced?}

On the constraint side, several factors were highlighted. Difficult staff was cited by 8 respondents, limited resources were cited by 18 of the student teachers. In addition, 10 respondents mentioned the uncooperative attitude from certain staff from a particular type of school. This is what a respondent said: the educator was difficult and selfish. She did not give me year plan, teaching aids. Another respondent pointed out: I was always struggling to get resources. Some teachers were mocking me in Afrikaans about my physical appearance. When probed further into what they meant by 'difficult staff' respondents explained that their mentors were not helpful and were unwilling to support them with resources and other help they required in terms of the work schedule, classroom activities and so forth.

Twenty one (21) respondents cited student misconduct as a major constraint they experienced during their work integrated learning exercise. A student-teacher stated as follows: learners were misbehaving whilst (I) am in class and I found it hard to punish them so I had to call one of the teachers to discipline those learners. Another respondent stated: learners were misbehaving and in that way it makes teaching not easy.

It was also revealed that supervisors/lecturers did not visit them regularly. Thirty five (35) respondents mentioned that they were supervised by lecturers only once as compared to the minimum requirement of two supervisions per student teacher. Only 10 out of 45 respondents indicated that they were supervised twice by lecturers from the university. Two students did not indicate how many visits they received from the university lecturers.

Besides, mentors from the schools were expected to assess and provide resources and support to these trainees through classroom visits. However, some respondents (12) mentioned that such visits did not take place and mentors only filled in the assessment forms at the end of the work integrated learning without any classroom visitations. Quality assurance is therefore compromised. A respondent commented: I had to struggle to get EMS textbooks, examples of lesson plan and the school work schedule and there were no class visits by my mentor.

Class attendance was also reported by some student-teachers as a major constraint. Ten (10) respondents mentioned this issue. One lamented as follows: students always came late coming and in grade 11 where I teach there are always absentees. Eighteen (18) student-teachers also singled out the issue of overcrowding in the classroom which made it difficult for them to reach out to all learners with classroom activities. A statement from one respondent refers to this: Most of the class were overcrowded with 52 learners and 60 learners in one classroom. Another respondent said this: ... the school is overcrowded, there are many learners in classes and this makes it easy for learners not to participate actively in the learning process and this makes the learning process too slow.

Culture of learning_was mentioned as a challenge and at least 24 of the respondents cited this issue. A studentteacher lamented: Some learners are too scared to participate which is a disadvantage to them. Another respondent said: some of the learners don't do the homework and they do not participate in class. Some laugh at others when answering questions. It was established that the student teachers need improvement with their questioning skills. It emerged from the assessment reports that questions posed by student-teachers were not clear, or intimidating, ambiguous or misdirected.

Chalkboard work was also cited as a problem by some respondents. At least 21 students mentioned that it was difficult to write and talk to the students at the same time and sometimes the class became rowdy whilst she/he is busy on the chalkboard. This is what a respondent said: writing notes on the chalkboard where I was not concentrating and that resulted in making a lot of mistakes. Another respondent said: I should have practiced how to use the chalkboard before going to work integrated learning.

\subsection{What are your suggestions for improving work integrated learning?}

Composite responses from the student-teachers are presented here. The respondents were requested to make suggestions to improve work integrated learning and the following were mentioned: The need to re-examine the work integrated learning schedule. There were suggestions by the BEd students that the current practice should be replaced by a year-long stay at schools for work integrated learning. One reason commonly given by the respondents was that a longer time is needed to gain experience and become more effective teachers. Eight (8) respondents were of the opinion that the duration of WIL should be extended from its current six weeks each semester for PGCE students. Some respondents were of the opinion that WIL should not be limited to only one specific province and instead student-teachers should be allowed to practice in any part of the country.

Thirty seven (37) out of the 47 respondents stated that there is not enough time for classroom activities due to other tasks, including school administrative work. To avoid the disruptions brought about by sudden changes in timetable, it was suggested that any time table changes should be done in advance. The researcher found out that this issue 
is related to organisation in the school pertaining to learning activities.

All 47 of the students' teachers indicated the need for intensive use and supply of LTSM and both university and schools should ensure their availability for effective teaching and learning. The lack of adequate and relevant resources disrupts learning activities. There is also the need to reduce paper work. Students also suggested that no assignments or projects for other modules should be given to them during the work integrated learning. Thirty five (35) of the respondents requested more visits by the university lecturers and student teachers should be informed in advance of such visits because 'surprise' visits unsettle them in class. Besides, the frequency of class visitations by lecturers should be increased or the current policy must be enforced to the letter so that student teachers receive regular visits by lecturers whilst on practice. Forty (40) of the respondents also suggested the need for financial allowance whilst on WIL which could support them for transport, food and other logistics. The bursary and student loans do not cover them whilst on work integrated learning. Such allowance would provide more stability and sustainability for some of the poorer students. Respondents also suggested that student-teachers receive thorough in-house preparation/training before being sent to schools. The preparation should include peer demonstration/teaching. This is an important issue for the training institution.

The number of students teachers placed_at schools should be controlled and instead of students placing themselves at schools, the university should take responsibility for this arrangement. There was a suggestion by some students that first year students should not be sent to schools until their $2^{\text {nd }}$ year. No rationale was provided but upon further investigation, the researcher found out that, contrary to the WIL policy, some schools place these first year students in classroom, not only as observers but also teachers during WIL due to teacher shortages in some schools. Perhaps these final year students observed that such practice leads to more learning and teaching disruption in schools.

\subsection{Inputs from the schools}

School Management Teams (SMTs), including principals, were requested to comment about the student-teachers performance. The following issues were raised for the improvement of the work integrated learning, including; studentteachers need to demonstrate effectiveness in classroom control; use a variety of teaching methods; provide for individual differences, demonstrate competence in subject matter, demonstrate skills in questioning; develop a questioning attitude and intellectual curiosity; secure learner participation in learning activities, show improvement in selfevaluation, develop effective processes of problem solving and critical thinking on the part of learners, use a variety of appropriate instructional materials, use vocabulary suitable to the developmental level of learners, write legibly and spelt correctly, use a variety of sound assessment techniques. Schools also request student-teachers to exercise emotional control and poise as well as accept and profit from constructive criticism.

\section{Discussions}

It is important to mention that the study revealed important human aspects which are not normally emphasised, namely, respect and a co-operative atmosphere in some schools. These positive aspects need to be identified and sustained in the teacher education programme since they are the foundation for confidence building which promotes effective teaching and learning. Nevertheless, the study findings also agree with Komba \& Kira (2013) that the organization of the Work integrated learning is faced with a number of challenges. The results of the study have revealed that there is the need for improvement in management practices to improve the effectiveness of the exercise if it is to continue to serve its purpose.

The issue of work integrated learning allowance is also very important due to the fact that a majority of these student-teachers come from a poor rural background. The institution where this study was contextualised and undertaken is surrounded by 22 villages from where the Faculty of Education specifically draws its student population. It is not uncommon to find most of these students having no access to any form of financial support when they are out of campus. Poverty and lack of access to transport and meals influence their commitment and confidence in managing the integrative and applied knowledge in the schools and classrooms during WIL.

The question that comes to light is whether these experiences and events related by these students-teachers do not influence their motivation and desire to be in the profession. It is not surprising that the results showed that 24 (about $50 \%$ ) of the respondents were not ready and not motivated to become teachers. In addition 25 (54\%) felt that the work integrated learning exercise in its current format is not effective considering the challenges they face. These challenges as analysed above are significant enough to influence the effectiveness of work integrated learning. Komba \& Kira (2013) pointed out that such challenges render Work integrated learning ineffective in improving teaching skills.

On the issue of the culture of learning leading to the problematic behaviour of learners in the classroom, the 
question here is to what extent the policies and post-apartheid educational changes have influenced this culture of learning among South African students. Considering the matric pass rate, the passing/promotion grades as well as the passing rate or throughput, the issue of the culture of learning still poses a challenge to the educational development of the country. Mpungose (2010) was of the opinion that these experiences and events are stories merely expressing connections to the past reality. Although Work integrated learning is generally accepted as an important contributing factor towards the quality of teacher education programmes, the findings of this study have revealed that it is difficult to obtain quality teachers, given the prevailing challenges (Komba \& Kira 2013).

\section{Conclusions}

The study however highlighted the following for improvement in the WIL to stimulate student-teacher interest and effectiveness: strengthening the content delivery to build more confidence among learner, strengthen the pedagogical approaches to improve student-teacher knowledge and skills in inclusive teaching, human development and learning, curriculum management, etc. and improving the work experience practices to enhance students skills in the use of chalkboard, LTSM, lesson planning, development and implementation. These findings should assist student-teacher recruitment and training as well as curriculum developers and implementers to enhance the content quality and delivery of Disciplinary Learning, Pedagogic Learning, Practical Learning, Fundamental Learning, and Situational learning of the new B.Ed. and ADT programmes to eliminate or at least minimise the challenges explored in the study and provide an effective WIL exercise for the BEd and PGCE programmes

\section{References}

Capel, C, Leask L. \& Turner T, (eds) (2013). Learning to teach in the Secondary School: A companion to School Experience. Routledge. London.

Cohen, L. Manion, L. Morrison, K. and Wyse, D. (2010). A guide to Teaching Practice $5^{\text {th }}$ ed. Routledge. London.

Departments of Basic Education and Higher Education and Training, (2011). Integrated Strategic Planning Framework for Teacher Education and Development in South Africa, 2011-2025- Basic Education Higher Education \& Training, Pretoria

Department of Education, (2006). National Policy Framework for Teacher Education and Development In South Africa. Pretoria.

Department of Higher Education and Training (2011). The Minimum Requirements for Teacher Education Qualifications. Government Gazette, No. 58315 July 2011. Pretoria

Flick, L.B. and Lederman N.G. (2001). The Role of Practice in Developing Expertise in Teaching. School Science and Mathematics. Vol. 101(7). 345-347.

Fraser, W J, Killen, R and Nieman, M. M. (2005). Issues in competence and pre-service teacher education. Part 2. The assessment of work integrated learning. SAJHE 19 (2), 246-259.

Jephcote, M, Abbot I 2005. Teaching Business Education 14-19. London: David Fulton.

Kiggundu, E. \& Nayimuli, S. (2009) Work integrated learning: a make or break phase for student teachers South African Journal of Education Vol. I 29:345-358.

Komba SC and Kira ES (2013) The Effectiveness of Work integrated learning in Improving Student Teachers' Teaching Skills in Tanzania. Journal of Education and Practice Vol.4, No.1.

Marais, P. \& Meier, C. (2004). Hear our voices: student teachers' experience during practical teaching. Africa Education Review, 1,220233.

Marton, F. and Booth, S. (1997). Learning and Awareness. Lawrence Erlbaum, New Jersey.

Marton, F. and Pang, M. F. (1999). Two Faces of Variation. Paper presented at the $8^{\text {th }}$ European Conference for Learning and Instruction. Göteborg, Sweden, August 24-28.

Mpungose, J (2010) Constructing principals' professional identities through life stories: an exploration. South African Journal of Education. Vol. I 30:527-537

Papier, J (2008). Policy, practices and persistent traditions in teacher education: the construct of teaching and learning regimes. Journal of Education. № 45.

Perry R (2004). Work integrated learning for early childhood. A guide for students. Available at http://www Routledge.com catalogues./0418114838.pdf. Accessed 20 July2013.

Shulman L, S. (1986) Those Who Understand: Knowledge Growth in Teaching. Educational Researcher, Vol. 15 (2) 4-14. 